\title{
Performance on delayed response tasks by patients with Parkinsonism ${ }^{1}$
}

\author{
DAVID J. DE LANCY HORNE \\ From the Institute of Psychiatry, Maudsley Hospital, London
}

SUMMARY Eleven post-thalamotomy Parkinson's disease patients, and 11 post-operative, age $\frac{\frac{\bar{C}}{\bar{N}}}{\frac{5}{5}}$ matched, spinal control subjects, were tested on three visual discrimination matching tasks, two of $\vec{\nabla}$ which involved a delay in response. Error and reaction time scores were recorded. The former produced no differentiation but reaction time scores were significantly faster for the control group on the two tasks involving delay in response but not for the 'no-delay' task. Since the motor? components of all three tasks were the same, this significant difference in reaction time scores was attributed to the factor of delay in response, and treated as evidence that basal ganglia damage in humans can produce a purely cognitive impairment. The role of sensorimotor interactions, as another factor in this deficit, was also discussed.

Concern about the possible roles of subcortical brain centres in mediating higher mental processes has recently become evident in the neuropsychological literature. Much of this work is reported in Riklan and Levita's recent volume (1969) entitled Subcortical Correlates of Human Behaviour.

In many studies, the vast majority of which have been concerned with cases of Parkinson's disease, the patients have been tested pre- and postoperatively using conventional standardized psychological tests. A major limitation of this type of study is that the standardized tests may miss detecting a true psychological deficit due to inappropriate sensitivity. Teuber and Proctor (1964) were aware of this limitation, and from the results of some animal and human experiments to investigate the effects of basal ganglia damage on perception, they hypothesized that sensorimotor interaction and delayed response were two important components for demonstrating a deficit in this area.

The present experiment was devised further to test these hypotheses, particularly that of delayed response. The question was asked, 'would interpolating a delay between stimulus and response demonstrate an impairment in the performance of

\footnotetext{
${ }^{1}$ This work was carried out in part fulfilment of the requirements for the degree of Master of Philosophy, London University.

${ }^{2}$ Present and reprint address: University of Melbourne, Department of Psychiatry, Clinical Sciences Building, Royal Melbourne Hospital, Victoria 3050, Australia.
}

Parkinson's disease patients that could not attributed to motor impairment?'.

\section{METHOD}

EXPERIMENTAL SUBJECTS Eleven patients with Park sonism (four men and seven women) acted as experiment subjects. They were tested between one and three weeks after receiving a thalamotomy operation. Postoperative testing was used in an attempt to gain some control over site and nature of lesion. Three subjects had left, three had right, and five had bilateral thalamotomies.

CONTROL SUBJECTS These were 11 patients in the same age range as the Parkinsonism group who had cervical spondylosis (eight patients: four men and four women) and prolapsed invertebral discs (three patients: two men and one woman). They, too, were tested between one and three weeks postoperatively, and are henceforth referred to as the 'spinal' group.

Age, Mill Hill Vocabulary (MH) IQ, and Raven's Progressive Matrices (PM) IQ were recorded for all $\exists$ subjects. As shown in Table 1, according to $t$ test results, the two groups did not differ significantly for mean age and MH IQ. However, on the PM test the spinal control group's IQ was significantly higher than that of the $\frac{\text { 의 }}{2}$ Parkinsonism group $(P<0.05)$. These findings are $D$ discussed below.

APPARATUS AND EXPERIMENTAL TASKS The main feature $N$ of the apparatus was a ground glass screen on to which $N$ slides could be projected from behind the subject who was seated $3 \mathrm{ft} 6 \mathrm{in}(107 \mathrm{~cm})$ away from the screen. A $\omega$ microphone was placed directly in front of the subject so 
TABLE 1

MEAN AGE AND LEVEL OF INTELLIGENCE

\begin{tabular}{|c|c|c|c|c|}
\hline & $N$ & $\begin{array}{l}\text { Age } \\
\text { (yr) }\end{array}$ & $M H I Q$ & $P M I Q$ \\
\hline Parkinson's & 11 & $\begin{array}{c}55.8 \\
(10.0)\end{array}$ & $\begin{array}{l}110.6 \\
(10.0)\end{array}$ & $\begin{array}{l}109 \cdot 4 \\
(12 \cdot 7)\end{array}$ \\
\hline Spinals & 11 & $\begin{array}{c}52 \cdot 0 \\
(11 \cdot 2)\end{array}$ & $\begin{array}{r}108 \cdot 3 \\
(9 \cdot 5)\end{array}$ & $\begin{array}{r}121 \cdot 8 \\
(8 \cdot 1)\end{array}$ \\
\hline$t$ test level of significance & & NS & NS & $P<0.05$ \\
\hline
\end{tabular}

SD in parentheses.

that his responses, which were purely vocal, could be recorded on to a tape. The tape also recorded the onset of each slide. Reaction times to the stimuli slides and error scores could therefore be calculated directly from the tape.

TASK I-LATENCY OF RESPONSE A stimulus slide of five designs (modified Chinese characters) appeared. The subject was required to call out, as quickly as possible, the numeral of the one of the four lower designs which was the same as the top unlabelled design (Fig. 1). There were 16 trials per subject. In this task there was no delayed response factor.

TASK II-SINGLE PRE-DELAY DESIGN WITH MULTIPLE POSTDELAY DESIGN A single modified Chinese character appeared on the screen. After a delay of either $10 \mathrm{sec}$ or $60 \mathrm{sec}$, the post-delay stimulus of four numbered designs appeared, one of which was the same as the pre-delay design. The subject called out its number as quickly as possible.

TASK III-MULTIPLE PRE-DELAY DESIGN WITH ONE CHARACTER UNDERLINED AND MULTIPLE POST-DELAY DESIGN The procedure was exactly the same as for task II except that there were four designs on the pre-delay slide, and the subject had to notice and remember the one which was underlined.

The order of presentation of tasks II and III was balanced between subjects, as was the length of delay period used. In all cases, however, task I was administered first. The positions of the modified Chinese characters on the slides were selected randomly, as also were the numerals employed as labels. The stimulus designs were chosen to minimize internal verbalization by subjects, but according to their introspective reports this was not entirely successful.

\section{RESULTS}

Error scores did not differentiate at all between the Parkinsonism group and the spinal group. Reaction time scores were converted to square root scores to reduce the degree of variance. These results are shown in Table 2.

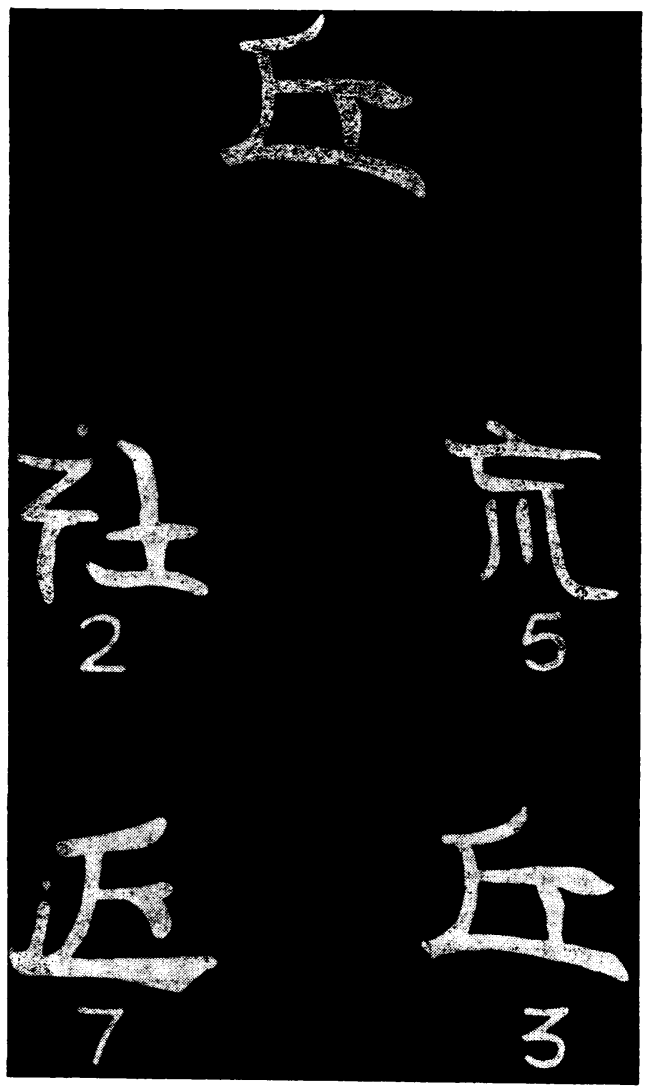

FIGURE Example of a stimulus figure in task I. Correct response by the subject for this stimulus figure is ' 3 '.

An analysis of variance showed significant difference between group $(P<0.05)$ and within group effects $(P<0.001)$.

As can be seen from Table 2, the Parkinsonism group's reaction times did not vary significantly on all three tasks, whereas, according to $t$ tests, the spinal controls reacted significantly faster on both tasks II and III than on task I $(P<0.01$ and

TABLE 2

MEAN SQUARE ROOT REACTION TIMES IN SECONDS

\begin{tabular}{|c|c|c|c|c|}
\hline & $N$ & Task I & Task II & Task III \\
\hline Parkinson's & 11 & $\begin{array}{c}1 \cdot 83 \\
(0.25)\end{array}$ & $\begin{array}{c}1 \cdot 75 \\
(0 \cdot 36)\end{array}$ & $\begin{array}{c}1 \cdot 77 \\
(0.35)\end{array}$ \\
\hline Spinals & 11 & $\begin{array}{c}1 \cdot 70 \\
(0 \cdot 17)\end{array}$ & $\begin{array}{c}1.46 \\
(0.18)\end{array}$ & $\begin{array}{c}1 \cdot 53 \\
(0 \cdot 12)\end{array}$ \\
\hline$t$ test level of significance & & NS & $P<0.05$ & $P<0.05$ \\
\hline
\end{tabular}

SD in parentheses. 
$\mathbf{P}<0.05$ respectively). Also, the differences between the scores on tasks 2 and 3 was significant for the spinal group $(P<0.05)$.

In the between group comparisons, $t$ tests showed that the spinal group had significantly faster reaction times on tasks II and III than the Parkonsonism group ( $P<0.05$ in both cases) but, very importantly, there was no significant difference on task I.

\section{DISCUSSION}

INTELLIGENCE The finding that the spinal control group had a significantly higher PM IQ than the Parkinsonism group $(P<0.05)$ does, in a very general way, concur with a hypothesis of perceptual impairment due to basal ganglia damage. However, other factors could have produced this result, such as biased sampling of the spinal controls, so that at this stage attention can be drawn only to the finding itself. Little can be made of its significance, without further study, in helping to understand the nature of cognitive impairment in Parkinson's disease.

DELAYED RESPONSE TASKS Successful differentiation between a group of subjects with basal ganglia damage, the Parkinson's disease group, and agematched controls, the spinal group, has been achieved by measuring reaction time in a relatively simple delayed response visual perception experiment. It is highly unlikely that the difference in the results can be attributed to poorer motor functioning on the part of the Parkinsonism group, because when no delay in responding was required there was no difference between the two groups (task I). Fatigue effects also appear to be ruled out, because with increasing task complexity (tasks II and III) the Parkinsonism group showed no deterioration in performance, while the controls actually improved theirs to a significant extent. Thus, this rather simple experiment has produced evidence to support the contention that basal ganglia damage may produce a deficit that is cognitive in nature and not $\underset{8}{Z}$ purely motor, as has hitherto commonly been $\stackrel{\mathbb{C}}{\mathrm{C}}$ believed. The parameter of delayed response appears to be a relevant factor for revealing this cognitive deficit, but in the present study the length of the delay itself (either $10 \mathrm{sec}$ or $60 \mathrm{sec}$ ) did not produces a significant effect.

In this study subjects were required to use a visual/ vocal sensorimotor interaction. Sensorimotor inter-. action factors have also been found important in $\Rightarrow$ eliciting a basal ganglia cognitive deficit by Proctor $\stackrel{5}{?}$ (Proctor and Cooper, 1964; Teuber and Proctor, 1964), using body-tilt and luminous line adjustments in the absence of any visual field, and by Talland $\frac{\text { s }}{7}$ and Schwab (1964) using some bead manipulation $₫$ and letter cancellation tasks. Thus, there do appear $\%$ to be strong grounds for believing that basal ganglia damage may produce cognitive changes over and above the motor changes that are well known to $\vec{\omega}$ occur. Some further studies are currently being undertaken by the author to try to define some of the relevant parameters more clearly.

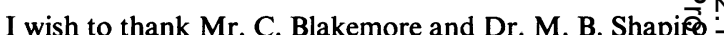
for their ideas and discussion of this project, Mr. Murrig Falconer and the staff of the Guy's-Maudsley Neurd surgical Unit for their practical help in supplying suitable $\supset$ patients, and Mr. N. P. Curwen for statistical advice.

\section{REFERENCES}

Proctor, Florry, and Cooper, I. S. (1964). Judgment of visư⿱⺌冋] and postural vertical by parkinsonian patients. Neurology (Minneap.), 14, 287-293.

Riklan, M., and Levita, E. (1969). Subcortical Correlates of Human Behavior: A Psychological Study of Thalamic and Basal Ganglia Surgery. Williams and Wilkins: Baltimore.

Talland, G. A., and Schwab, R. S. (1964). Performance with multiple sets in Parkinson's disease. Neuropsychologia, 2, 45-53.

Teuber, H-L, and Proctor, Florry (1964). Some effects of basal ganglia lesions in subhuman primates and man. Neuropsychologia, 2, 85-93. 